\title{
THE HEALING FORCE OF FAMILIES PROVIDING HELP FOR THOSE SUFFERING FROM PSYCHOSIS
}

\author{
LOBBAN, F. \& C. BARROWCLOUGH, eds. (2009) A Casebook of Family \\ Interventions for Psychosis (London: Wiley-Blackwell) 375 pp., 22.8x15x2.4 cm, \\ ISBN 9780470027080, $€ 92.90$.
}

\section{Family therapeutic approach of psychotic states}

It is obvious, that the treatment of psychotic states cannot be performed without the involvement of the closer supporting network (mostly families, although some schizophrenics are either homeless or residents of a common lodging house) surrounding the patient. The patient himself / herself often does not even recognise his / her illness, cannot even ask for help at first - those living around him / her identify the problem. So the main message of this book - the family approach of the handling of psychotic states - should not be new to anyone working in the medical field. Still, it seems that it needs to be outlined, because unless focusing on it directly, it might be forgotten, sadly enough. It should be evident for everyone working with psychotic patients to get in touch with the relatives, at least for obtaining case history data, and providing a minimal psychoeducational intervention.

So the idea itself of treating not just the patient but also involving family members is common; however, the methods in everyday health care are usually uncertain. The editors outline that according to given studies, simple short education or counselling programs used as a family approach in schizophrenia do not affect relapse rates: a few lessons on schizophrenia were not enough to change the underlying complex belief systems that exist within the family, and the learned new interaction skills were not used among family members after the psychoeducation. So how could we provide help more properly? The great advantage of this book is that it defines the specific steps to be taken, in order to get the best outcome possible, using the guidelines of evidence-based practice. The methods are introduced through case histories; therefore it is easy to put into practice what is learned. This book differs from many manuals and other writings in that rather than describing what to do 'in theory', this gives detailed accounts of what actually happens 'in practice', including managing situations that may arise unexpectedly. 


\section{On mission - and whom it reaches out to}

The book is a huge work done, and carried out profoundly, exhaustively, about the family interventions of psychotic states. (I have to note though that it uses exclusively the cognitive behavioural approach, I sometimes missed the cross references to other optional family therapeutic approaches.) The demonstrations of case studies and the health care systems are punctual, easy to understand, detailed, and therefore can be transformed to practice easily. It can be felt that the writers are on a mission of spreading their work methods, which are worthwhile using, as they experienced. The mission reaches out to many target groups, such as relatives, patients, different professions occupied in health care systems, and the leadership of health care and funding. It is the great richness of the studies mentioned that makes this reading useful for all these people.

\section{Contents}

Each chapter begins with an overview and gives some context to the case includeing the theoretical background of the clinician, a description of the wider clinical service, and some information about the therapist(s). A detailed account is then given of the process from referral into the service, assessment, formulation, intervention and critical reflection. Finally, the authors highlight the main conclusions from the given case.

The first chapter is written by the father of a young schizophrenic patient. It highlights the difficulties that families face in coming to understand what has happened. It describes how the family became involved in a family intervention, and in what aspects it was important for them.

The next three chapters all focus on first episode psychosis, the importance of offering support to families at an early stage, as soon as they need it. Helping families to understand psychosis and to find effective ways to manage it can reduce the development of unhelpful coping strategies and beliefs. Chapter four shows how family members can also become important agents in preventing relapse by learning to recognise early warning signs of it.

Chapters five and six are about interventions explicitly designed to address issues associated with psychosis and drug use; a mainstream of these interventions is motivational approach, such as motivational interviewing. Chapter five also presents how drug use might influence the evolution and procession of the psychosis. In chapter six we can read about a group intervention for relatives of people experiencing psychosis who use cannabis. The group aims to facilitate family members to learn how their own behaviour can influence both the drug use of the patient and their own levels of distress.

Chapters seven to ten describe single family cases that highlight the variety of specific issues that clinicians are likely to face when offering a family intervention service. Chapter seven describes how cognitive behavioural interventions can be used to 
modify the family's day to day interaction. Chapter eight focuses on helping the grief process of family members associated with the impact of psychosis. In chapter nine we can read about the importance of including siblings in our work with families, and it also describes the ways in which this can be done. Chapter ten is devoted to the issue of working with families from different cultural and ethnical backgrounds; we can read about the treatment of a black and minority ethnic family, how the background can cause specific challenges.

From chapter eleven the focus is more on the context in which the interventions are offered. In chapter eleven we can get to know the inspirational technique of using multiple family groups, while chapter twelve describes how family interventions can be done when the patient is currently at a ward of a psychiatric hospital as an inpatient.

Organisational issues are presented in chapters thirteen and fourteen; they describe the experience of setting up family interventions services in the National Health Service of the UK.

The last chapter allows us to give the final word back to the relatives. In the face of being unsupported and often excluded by services, relatives in the UK formed an independent charity (the COOL approach) which offers a range of services to relatives.

\section{Highlights}

As far as my own practice is concerned, what I found most useful reading are the cases of substance use in chapters five and six, the multiple family groups in chapter eleven, and some case histories where cognitive methods were used to keep a check on the parents' exaggerated anxiousness regarding their psychotic kid's independent steps, such as going out in the evening with friends, etc. The studies point out that substance use is very common among psychotics; cannabis use in people with psychosis turned out to be forty-two percent for lifetime use and twenty-three percent for current use, still, it is far less cited in the literature how to handle these complex cases, where the relapse rates are higher and the family arguments are usually intense. The model introduced in this book puts emphasis on reduction of harm rather than on immediate abstinence, training the parents in motivational interviewing, so that they can adapt to their child's state of motivation (pre-contemplation, contemplation, preparation, action, etc.) regarding the diminishing of substance-use.

The other idea that I found especially useful and one I would love to try out is the multiple family group setting. It is an up to date, new approach; at some conferences I have already heard about it, but never in detail. The main idea is to bring together more families and work with them in a group, in this case with the group of relatives of psychotic patients and the service users themselves. The setting, frames, topics are so carefully introduced in detail, that it could be easily adapted and worthwhile trying right away. The great advantage of the approach is that it is 'a discrete package of care, 
its modular nature uses staff time economically, it is easy to cost and to identify recourses, it makes use of and builds on staff's existing skills'.

The book covers a great spectrum of family interventions and theoretical backgrounds, such as behavioural family therapy, cognitive behaviour therapy, systemic family therapy, motivational interviewing and stages of change model, compassionate mind therapy, relapse prevention and early signs monitoring. Settings show a great variance as well, such as a single therapist working with single families, two therapists working with single families, multiple family groups, interventions in which the person with psychosis is present and those in which they are not, young siblings present or not and a variety of short interventions of less than ten sessions, to interventions lasting many months or even occurring over several years. The cases are led by a range of professionals, such as psychologists, nurses, social workers, and family therapists. The core of all case histories is mostly BFT, behavioural family therapy; this is the common denominator of the practice introduced by the editors. Although rarely do we meet families with a psychotic member in practice, who could gain more (and only) from other family therapeutic approaches such as the object relational, systemic, or strategic perspective, it is true that in the majority of cases the BFT method introduced in this book could be of a great help and an adequate handling of the problem. Let us not talk about the few exceptions that prove the rule. Methods are just partial coefficients anyway; non-specific therapeutic tools are also of great importance. The personality of the therapist is a therapeutic tool itself as well, for example in the case example introduced in the first chapter the two family therapists are amazingly receptive, flexible and enthusiastic, and these features help them through critical periods, not just the methods used. For example, they held the sessions at the family home and did not insist on the patient himself being present at the session by force, but left the lounge door open so they avoided the patient getting too sensitive, and slowly, even though not motivated first, he joined the sessions, at the beginning just for ten-fifteen minutes, still in a psychotic state. So, aside from the methods, personal qualities count just as much. (Note that for the therapists mentioned, this case was their first family intervention of a psychotic patient.) And, no matter what theoretical background is preferred, family-based care of psychosis should be fostered. The behavioural type of interventions can be educated and adapted easily, for complex health care systems it is a good choice to build on. And we must admit, in accordance with the editors, that one swallow does not make a summer: family-based care of psychotics should be introduced at an organisational level. It makes little difference if only a couple of enthusiastic family workers provide care locally, for a couple of fortunate service users. If we think of great numbers, the BFT approach could be a widespread basic care provided for those in need. It is tested, already introduced at an organisational level in many localities, tried out and passed, as the case examples of the book show. It is a great treasure of this book that it tries to serve the goal of systemic development, and gives examples and advice on how to reach this goal. The editors outline that clinicians' inability to prioritise family work is often due to not having sufficient

\footnotetext{
${ }^{1}$ P. 238.
} 
time for family interventions, having difficulties in integrating it with other responsibilities, or the lack of support from colleagues and the lack of supervision. These issues could be, and should be solved on the level of the constitution of clinical services. It is hard going against the flow, so the whole river should change direction, one could say. Sounds like a mission impossible, but it is not: the steps to be taken one after the other are written down in chapters thirteen and fourteen. Among the many suggestions we find in-house training of the whole staff or a great number of them, providing constant supervision, creating a part-time coordinator post, etc. A given proportion of trained family workers among staff members should be maintained, because sustainability is a main issue. It can be easy to get something started, but maintenance requires a continued commitment from people who champion this type of work - one can read among the wise pieces of advice.

So let us dream together, have the courage to dream about the change of services, and let us take the steps required to make an advance on this road. For the most of us, everyday work is done among improving but not ideal circumstances, service models. We try to provide care however we can, at least for those who we can reach. And it is worth doing so: for that given family it does make a change, even if it is only a drop in the ocean. As a father of a psychotic patient writes in this book:

I would not wish it on anyone but we do spend quite a lot of our lives not doing very much, and doing something that is difficult, even dangerous, but which really helps another person and knowing the difference it has made, has turned this experience (the care of his psychotic son) into something that I now feel good about. I only wish that in the darkest time I had known that to be possible. ${ }^{2}$

\section{Afterword}

As an afterword let me outline once more the main message of the editors of the book, which I can consort with: family work done with families where a member experiences psychosis should be advanced and dispersed. As in Great Britain the National Institute for Clinical Excellence Guidelines for services for people with psychosis states: family interventions should be offered to a hundred percent of families of individuals who have experienced a recent relapse, are considered to be at risk of relapsing, or who have persisting symptoms, and are living with or in close contact with their family. The rationale for this is very clear: because of the age of onset of psychosis, many young people are still living with or in close contact with their parents, many have young brothers and sisters affected by the disease, others are already in relationships and are parents of young children. Family interventions can help recovery and prevent relapse, and the family members themselves also often need help due to the loads of the impact of the disease: so the reasons to help families are diverse. Research found that short education or counselling programs do not affect relapse

\footnotetext{
${ }^{2}$ P. 352.
} 
rates, the underlying complex belief systems in the family need to be reached in order to make a difference. Behavioural family therapy can be one adequate tool to reach this aim in the majority of cases, especially if embedded in a family oriented health care system. 